\title{
Effects of increased traffic volume and speed heterogeneity on the capacity of a railway with dense mixed traffic
}

\author{
J. Warg \\ Division of Traffic and Logistics, KTH Royal Institute of Technology, \\ Stockholm, Sweden
}

\begin{abstract}
Increasing demand for train travel implies a need for improved traffic. More frequent departures and new regional stops have to be coordinated with the desire to shorten travel times for passengers and on the same line be mixed with freight operations.

This paper analyses how increased traffic predicted for 2020 affects the capacity of a 400-km section of the Southern Main Line in Sweden, a highly-utilised double-track line with heterogeneous and dense traffic with low punctuality, particularly as regards high-speed trains. In a second step, the consequences of raising the maximum speed for high-speed trains from 200 to $250 \mathrm{~km} / \mathrm{h}$ are analysed. The purpose of the paper is to show the effects of these measures and discuss strategies for improving punctuality and increasing timetable flexibility based on the revealed weaknesses of the system by combining timetable analysis and simulation.

The evaluation shows that an increase in traffic volume and speed differences leads to a decrease in the flexibility and reliability of the timetable. The punctuality of the high-speed trains becomes unacceptably low. The tested approaches to normalise the effects of increased traffic and speed on flexibility and punctuality are shown to be insufficient. Capacity utilisation on the line is so high that recovery is not possible.
\end{abstract}

Keywords: railway operation, capacity, simulation, delay, timetable flexibility, mixed traffic, Green Train, high-speed trains. 


\section{Introduction}

Market demands aim for shorter travel times, more departures and new stops for railway services. On highly-utilised lines with heterogeneous traffic, this is difficult to realise without negative impacts on the system's capacity.

In the Green Train research project (in Swedish Gröna Tåget) [1], a train concept for using conventional Swedish lines more efficiently and with higher speeds is proposed. Today, traffic on most of the Swedish railway network is mixed. High-speed trains, freight trains and regional services with lower speeds and more stops in most cases share the same infrastructure. Only some lines allow services to be separated.

This paper focuses on a 400-km section of one of the most important lines in Sweden, viz. the Southern Main Line. High capacity utilisation due to heterogeneous traffic with high frequency makes this double-track line sensitive to delays and limits possibilities for new traffic and maintenance.

Possibilities for increasing traffic and speed on such a line will be analysed. Aggravating the variances in speed by raising the maximum speed from 200 to $250 \mathrm{~km} / \mathrm{h}$ for high-speed trains and introducing new stops for regional services is expected to affect timetable flexibility, capacity and reliability negatively. Similar consequences can be assumed when services gets denser and new ones are established. These impacts will be identified and measures to decrease or normalise them found.

For this purpose, scenarios for future traffic (2020) and increased speed for high-speed trains are developed and analysed. By combining timetable analysis and simulation, both timetabling and quality aspects can be evaluated. Simulation has the disadvantage that it is connected to a single timetable, which means that it tends to show the effects of just this timetable instead of focussing on the general characteristics of the mix of services. The method that is developed in this paper aims to reduce this weakness by basing the choice of timetable to be simulated on the results of the timetable analysis.

\section{Related research}

Many approaches have been applied to define capacity on double-track lines. The timetable compression method defined in UIC Code 406 is a standardised way to evaluate the capacity of a line. Lindner [2] criticises the code in that it only focuses on line sections while disregarding nodes and the fact that misunderstandings in application can arise. Simulation analyses railways at a detailed microscopic level and attempts to reproduce the operation as realistically as possible. Radtke and Bendfeldt [3] describe how this is done with the timetabling and simulation system RailSys. Sipilä [4] applied this tool for the existing timetable and found strategies to improve reliability, for example by increasing the headways between high-speed trains and other trains. Lindfeldt [5] stated that the chosen timetable is crucial for the simulation results. As defining capacity by simulating just one timetable is said to be questionable, he developed a method for simulating numerous timetables with statistically varying and 
combining variables. It is shown that especially speed differences have huge impacts on the capacity of a double-track line.

Lindfeldt [6] also looks at the impacts of different timetable and infrastructure aspects on timetables. Using combinatorial timetable analysis in TVEM (Timetable Variant Evaluation Model), he shows among other things that the distance between overtaking stations on double-track lines becomes more important as regards scheduled delay with increasing speed difference and frequency of operation. By simulating theoretical and practical cases, Vromans [7] and Vromans et al. [8] also show that the heterogeneity of a timetable influences the reliability of the railway services to a high degree, but emphasise that the most effective way to use a railway as regards reliability is often not the most preferable way of satisfying railway users.

Another approach to defining capacity is optimisation. Castillo et al. [9], for example have developed an optimisation algorithm for timetabling that includes, among other parameters, travel and dwell times, headways, fuel consumption and passenger preferences.

\section{Methodology}

Many ways to analyse and define capacity were shown in the literature review. In this project, capacity is defined as timetable flexibility and reliability and evaluated as characteristics such as number of possible timetable alternatives, train slots, delays, punctuality and recovery, etc. Evaluation is done by merging combinatorial timetable analysis and microscopic simulation. In order to analyse the effects of increased traffic and higher maximum speed, a scenario similar to today's traffic is compared to two scenarios with increased traffic (with and without increased speed for the high-speed trains) in the following way (Figure 1):

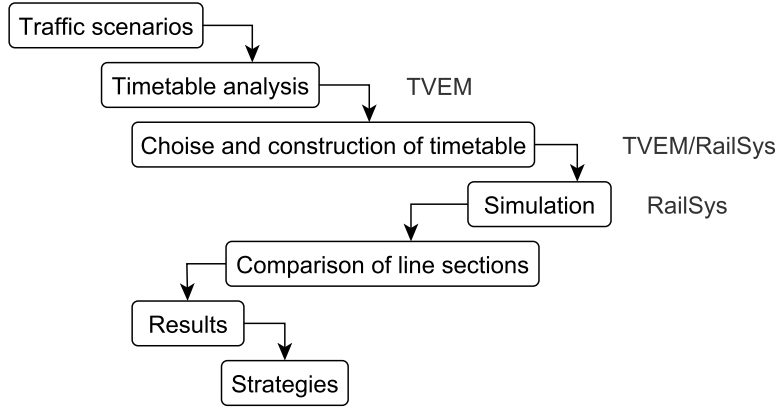

Figure 1: Description of method.

After specifying the base alternatives and defining the kind and frequency of service for each alternative, running times are calculated in RailSys and timetable analysis executed using TVEM. Based on this evaluation, the most preferable timetable is chosen to be evaluated in RailSys. An analysis comparing the different parts of the selected line reveals characteristics that might influence 
the behaviour shown in the simulation. The results for the different scenarios are compared and used for defining strategies for ameliorating the system. These strategies are analysed in a similar way, with details and steps adjusted to the specific alternative.

\subsection{Definition of traffic scenarios}

For the three scenarios with and without increased traffic and speed, simplified periodic timetables for passenger traffic's peak hour are developed. By structuring the timetable for 2011 and choosing a representative level for the peak hour, the kind of services (stops, train type etc.) and departure frequency to choose for the base scenario 2011 are defined. Existing and desired relations between departures of the same or different services are considered. For the increased traffic level, 2020 is chosen as reference year. The amount of traffic is developed based on the chosen traffic for 2011, future plans, on-going studies and predictions.

\subsection{Timetable analysis and simulation}

The defined traffic is analysed with the MatLab-based combinatorial timetable evaluation tool TVEM where infrastructure is modelled and traffic systems defined by among other parameters frequency, headways, priority, train order, maximum scheduled allowance (on the line and for scheduled stops for overtaking), priority, running times and stops. Running times are calculated in RailSys, including allowances based on the scheduled times today. Using these preconditions, the program places the services after each other in the timetable in order to find all possible timetable alternatives based on the input data. For the last train in order, the program shows all possible slots. Due to limitations in TVEM, the number of train systems to be analysed in TVEM is reduced to seven.

The timetable alternatives found are evaluated by comparing characteristics that are important for the chosen line, for example number of possible timetables, average scheduled delay, possible headways and additional slots. The timetable that is shown to be most favourable is implemented in RailSys and complemented with the services that are not considered in TVEM. Due to the additional services and the higher level of detail in RailSys compared to TVEM, adjustments have to be made. In contrast to the timetable in TVEM and the real one, departure times are not fixed at full minutes in RailSys.

Simulation is done for 200 cycles of a periodic timetable for eight hours. Both entry delays and primary run and dwell time extensions estimated and adjusted based on Sipilä's previous studies [10] are used to model the disturbances to the services. The model is calibrated according to this research. By evaluating delay and punctuality developments for different train types on the entire line section, reliability can be shown for each scenario. Together with the results of the timetable analysis, these values are used to compare the scenarios to determine how increased traffic and speed differences affect capacity. 


\subsection{Comparison of the different parts of the line and strategies for improving timetable flexibility and reliability}

Based on services entering and exiting the line, it is divided into parts without changes in traffic supply. These parts are analysed in respect of total traffic volume, distances between passing stations and differences in average speeds. The analysis focuses in particular on the parts where timetable analysis and simulation showed substantial negative effects from the increased traffic and/or speed differences. Possible sources are identified and strategies for improving the weak parts defined and tested. Combining the measures is also evaluated.

\section{Studied case}

\subsection{Background}

The method was applied on the passenger traffics' peak hour for the south-bound direction of the selected electrified double-track line between Katrineholm and Hässleholm in southern Sweden. The section is part of the Southern Main Line, one of the most important railways in Sweden, connecting as it does the capital Stockholm with Sweden's third city Malmö and, via Denmark, central Europe (Figure 2).

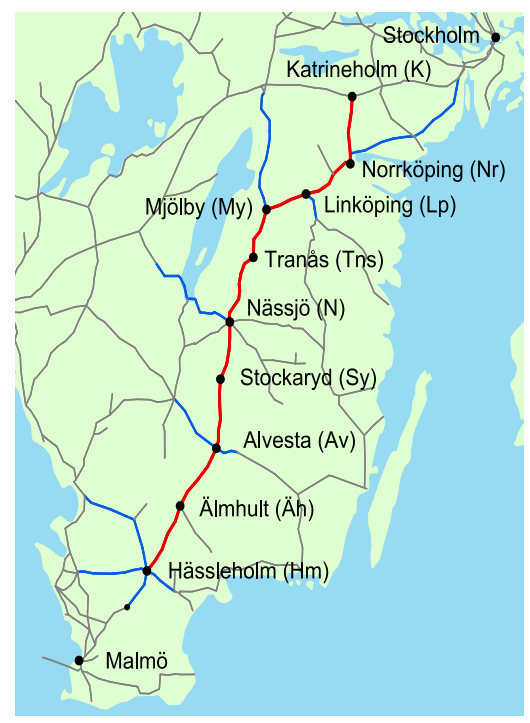

Figure 2: $\quad$ Selected part of the southern main line.

The line is used by various different freight and passenger services. Today's timetable is heterogeneous both as regards train types and departure times. Periodic timetables are desirable, but difficult to realise due to the high capacity utilisation and the mix of traffic. 
According to the Swedish Transport Administration's evaluation, capacity utilisation during the two-hour maximum according to UIC 406 is medium on more than half of the analysed section (54\%). This indicates an increased risk of delays and difficulties resulting from changes in the timetable. Even worse is the situation for the $12 \%$ of the line where high capacity utilisation is indicated [11]. Utilisation compared to demand for train slots gives similar results [12].

\subsection{Traffic scenarios}

As stated earlier, the traffic scenarios are developed based on the timetable for 2011 and predictions for more departure, new services and new stops for regional/commuter trains on the southern part of the line. In the scenario with increased speed, the Green Train [13] concept is used: A high-speed train adjusted to Swedish preconditions and developed for operation with increased speeds on existing infrastructure thanks to carbody tilt. Speed profiles are derived from [14].

The structures shown in Figure 3 are found to be representative of the considered part of the Southern Main Line: Two different high-speed services and one InterCity (IC) train use the entire section; all other systems only parts of it. In the scenario for 2020, denser departures are planned for the high-speed train with fewer stops, the IC train and one of the regional trains (every hour instead

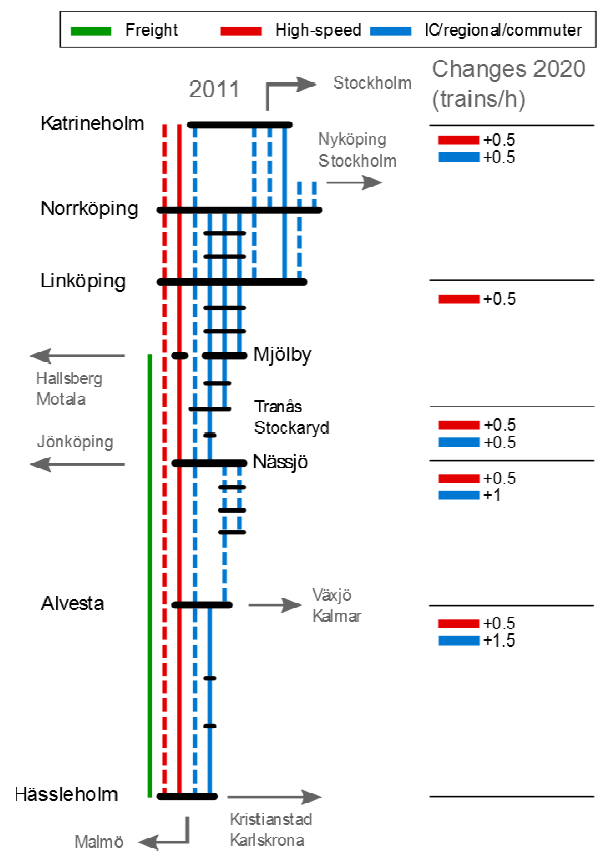

Figure 3: Peak-hour traffic for scenarios 2011 and 2020. Vertical lines: departures/h per direction (dotted: every two hours). Horizontal: stop for passenger exchange. 
of every other hour). In the southern part, there is a new regional system. This system and another one further north are assumed to use new regional stops. Due to changed destination, there is also a regional system with reduced use of the line compared to today's scenario.

\subsection{Timetable analysis in TVEM}

The analysis in TVEM includes the three services using the whole of the chosen section (two high-speed trains and an IC train), three commuter trains and a freight train. The freight train is the system chosen to be placed last in the timetabling process, which means that all remaining capacity after placing the first six trains is used to allocate freight train slots.

The number of possible timetables is used as an indicator of flexibility in each scenario. All found timetables for each scenario are evaluated and graded based on the following characteristics (in order of priority):

- Headways between commuter trains (even and customer-friendly spread)

- Number of slots for freight trains

- Scheduled delay for high-speed trains

- Scheduled delay for IC train

- Average scheduled delay for freight train(s)

The headway between the commuter trains is very important on the considered line. From a market point of view, evenly spread departure times are the most effective method. Due to the commuter trains' low average speed, this does not leave enough room to accommodate the other trains unless large supplements are accepted for faster trains. Supplements are in conflict with the aim of the high-speed trains as they lead to longer travel times.

Figure 4 shows the timetable with the best properties according to the evaluation used for the scenario with increased speed and traffic. Two freight trains per hour can be scheduled.

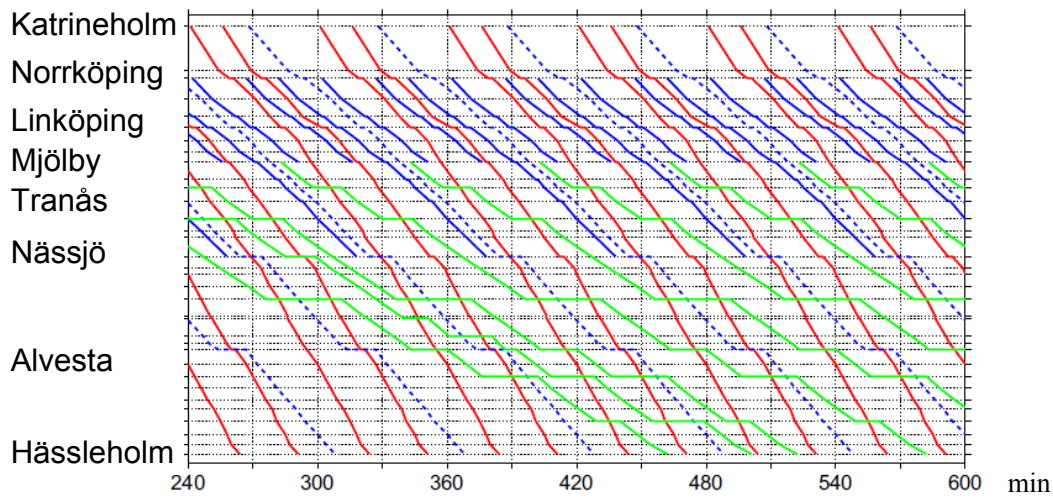

Figure 4: Timetable generated in TVEM (scenario 2020 with increased speed for high-speed trains). High-speed trains: red, commuter trains: blue, IC train: dotted blue, freight trains: green. (See online for colour version.) 


\section{Results}

Complemented with the remaining nine services and adjusted to the more detailed level in RailSys, the chosen timetable for each scenario is simulated and analysed as described before. In connection with an analysis of the parts of the lines, strategies are developed and evaluated.

\subsection{Effects of increased traffic and differences in speed}

\subsubsection{Timetable flexibility and properties}

With the defined limitations for maximum scheduled delay, an even spread of the departures of the commuter trains cannot be achieved in any scenario. Factoring customer-friendliness into the criteria for choice of timetable, the intervals 15-20-25 are chosen in all scenarios. Possible spread differs only by a small amount between alternatives; however, it is worse in the scenario without traffic increase where one of the commuter trains uses a longer section of the line compared to the future scenarios.

Increasing traffic decreases the number of possible timetables significantly. This effect is intensified by increased speed differences. In addition, the number of possible slots for freight trains is reduced from three per hour in the base scenario to two in the scenarios with increased traffic.

Denser traffic and higher speed variation also affect the scheduled delays. Waiting times for overtaking for both the IC and the freight train are much longer than in the base scenario. Compared to the total running time without stops due to capacity limits, they lose up to $14 \%$ and $46 \%$ respectively. Table 1 shows the results of the timetable analysis.

Table 1: $\quad$ Timetable properties.

\begin{tabular}{|l|r|r|r|r|}
\hline & \multicolumn{3}{|l|}{ No. of } & \multicolumn{2}{l|}{$\begin{array}{l}\text { Supplement in RailSys [\% of } \\
\text { undisturbed running time] }\end{array}$} \\
\hline Scenario & Timetables & freight slots per hour (max) & IC & Freight \\
\hline 2011 & 305 & 3 & 2 & 26 \\
\hline 2020 & 184 & 2 & 14 & 41 \\
\hline 2020 increased speed & 17 & 2 & 11 & 46 \\
\hline
\end{tabular}

\subsubsection{Reliability}

As delay inputs are calibrated to fit today's delay level, commuter trains have high reliability, while high-speed trains in particular suffer high entry delays in Katrineholm and with that low punctuality in the simulation from the outset. Figure 5 shows the simulated results for punctuality development:

Punctuality for high-speed trains decreases and average delays increase along the line in all three scenarios. Punctuality falls earlier in the scenario for 2011, which shows that the impact of the commuter service using a longer part of the line in that scenario outweighs the effect of more departures on that part of the line in the future scenarios. However, this effect is normalised on the last part of the line, where new regional services and stations are introduced in the scenarios for 2020. While the high-speed trains can keep their 2011 punctuality level, a 


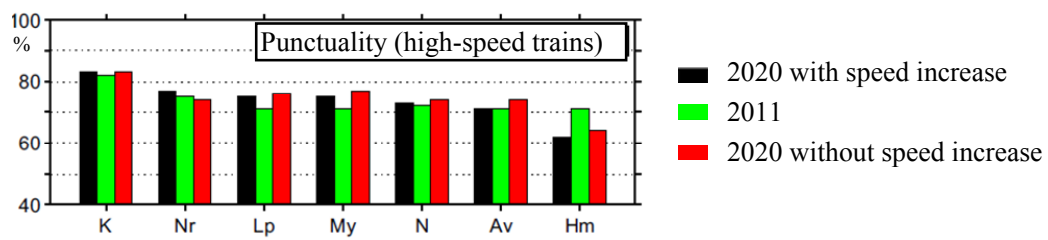

Figure 5: Punctuality for high-speed trains in the three base scenarios (less than six minutes late at departure from stations).

substantial decrease occurs in the scenarios for 2020, especially when higher speed for high-speed trains is introduced. The final level of punctuality, between $62 \%$ and $71 \%$, is not acceptable.

Even for the other services, secondary delays grow with the increase of speed and traffic volume. Regional trains that have low primary delays and only use a part of the line are not affected in a big amount. Freight and IC trains are influenced in a higher degree, even if they can recover some extent of delay by using not-needed scheduled allowance in case of rescheduling.

\subsubsection{Comparison of the different parts of the line}

Simulation showed that the biggest loss in punctuality occurs on the last part of the line. Comparision of the sections' preconditions shows that this is characterised as a long distance with significant differences in average speed, many departures and quite long distances between overtaking possibilities. Together with the previous section, these are the parts with the longest sections with highest maximum speeds for the high-speed trains. With the increased traffic volume, the last part is also the section with most new regional services and stops. Trains running at high speeds are more sensitive to disturbances when speed is reduced as braking occurs from and acceleration to higher speeds and because they have to adjust their speed if they end upp following a slower train.

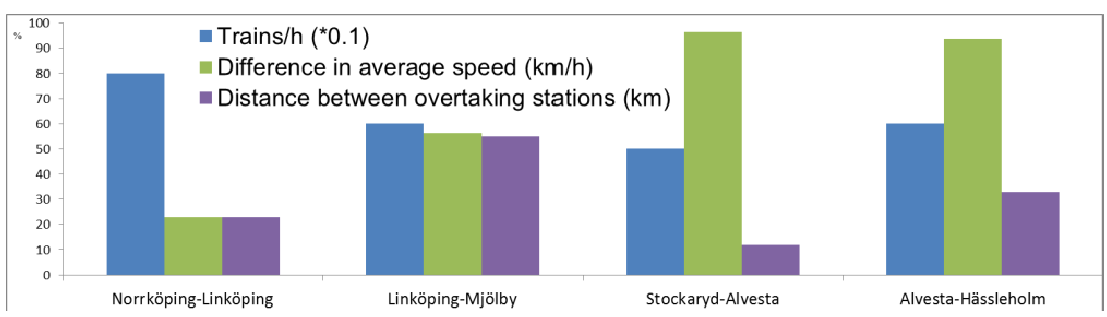

Figure 6: Comparison of sections of the line (selection).

Figure 6 compares some characteristics of four of the line sections for the scenario with increased speed and traffic. There are sections with greater speed differences, more trains and greater distances between overtaking stations than the last one. However, these parts of the line have lower values for the other characteristics, which shows that that particular mix - high differences in 
average speed, dense traffic and few overtaking stations - makes the section the most sensitive to secondary delays. Of particular interest is the comparison between the first and last parts of Figure 6: Despite 50\% more departures per hour, the changes in punctuality between Norrköping and Linköping are tiny compared to Alvesta and Hässleholm (see Figure 5).

\subsection{Strategies for improvements and their effects}

Timetabling flexibility of the analysed line is shown to be low and demands for increased traffic and shorter travel times cannot be realised unless low reliability is accepted. However, there are strategies to decrease these negative impacts.

One strategy is to find ways to reduce dwell time delays. As shown, the long-distance trains on the line suffer from low reliability. Dwell time delays contribute to this. Statistics from 2007 show that around 40\% of high-speed trains in Sweden exceed the scheduled stopping time of two minutes (SJ AB, 2007). For the Green train, a better door arrangement has been developed to speed up the boarding process. Simulation confirms that this is an effective way to keep the schedule at stations and reduce the overall delay, but not so much that it can normalise the effects of increased speed and traffic with reduced dwell time delays. Further variation of the dwell time delay or strategies to reduce other disturbances might be of interest to investigate in further analysis.

In the future scenarios, reliability is shown to be worst on the last part of the line, a long section with high traffic volume and mix. Additional scheduled allowance for the high-speed trains on that section reduces the differences in average speed. By adding extra time to one of the two high-speed services, an overtaking of a regional train can be skipped which increases the average speed of this service and leads to a more homogenous flow. Punctuality increases for all services, especially for the high-speed trains. The average loss in punctuality between Katrineholm and Hässleholm is halved to ten percentage points. By also adding extra allowances to the second high-speed service, the overtaking of the freight train can also be skipped. Despite time gains, the freight train's punctuality is affected positively. For the high-speed trains, these changes in the timetable affect reliability so much that the huge decrease in punctuality on the last part of the line in the base alternative turns into a small increase.

Increasing the maximum speed of the freight trains from 100 to $120 \mathrm{~km} / \mathrm{h}$ also reduces the speed differences. Analysis in TVEM shows that this reduces the total time for freight trains by $23 \%$ and makes room for an additional train slot. As the freight train is defined to be the last one to be placed in TVEM, the speed change does not affect the choice of timetable. In RailSys, where more services are scheduled, the time gains are lower than in TVEM. Simulation shows that increasing the speed of the freight trains improves their reliability, especially on the last part of the line. However, the impact on other trains is low.

Without the new stops for regional services on the southern part of the line, higher average speed can be achieved. Timetable analysis of the scenario for 2020 with faster trains but without new stations shows increasing flexibility and possibilities to reduce the scheduled allowances. Overtakings can be eliminated in some cases, which not only reduces the timetable time for the train that skips 
waiting for trains with higher priority, but is also shown to have positive impacts for the high-speed trains due to lower time loss if they are following a regional train.

Skip-stop is also tested for the commuter trains on the northern part of the line. As speeds are already adjusted in that part, this does not lead to huge flexibility gains. However, if some of the services become faster due to skipped stops, the space between the departures defining the slots of the long-distance services changes. Fleeting of high-speed trains becomes possible. Short intervals between departures of the same kind is not preferable from passengers' point of view, but leads to around ten percentage points higher punctuality for the high-speed trains compared to the original alternative.

Halving the distances between overtaking stations is tested on the southern part of the line. This leads to better timetable flexibility. However, the effects on reliability are small.

Additional scheduled delay for the high-speed trains is shown to be the most effective strategy. However, none of the tested strategies succeeds in normalising the negative effects of speed and traffic increase. Neither can the entry level be reached.

By combining the strategies, reliability can be strengthened. Figure 7 compares punctuality at the final station on the selected line. Combining additional scheduled allowance for high-speed services or skip-stop and fleeting with lower dwell time delays is shown to be the most effective methods.

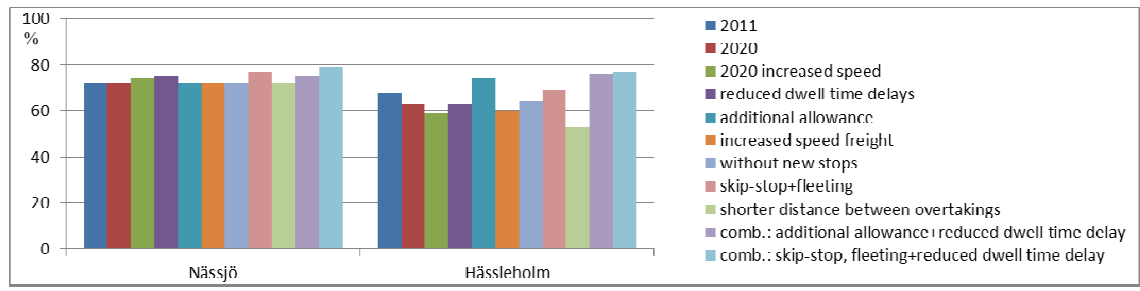

Figure 7: Punctuality in Hässleholm for high-speed trains (percentage of trains that arrive less than six minutes late). Entry punctuality: $83 \%$.

\section{Conclusions}

Combining timetable analysis in TVEM with evaluation and simulation in RailSys to analyse periodic timetables for a given mix of services makes the results more reliable and strengthens the comparability of alternatives. However, these advantages were limited by the fact that not all services could be included in the analysis in TVEM and due to the differences in level of detail in the two tools.

For the selected line with dense heterogeneous traffic, increasing traffic is shown to have significant impacts on timetable flexibility and reliability expressed by the analysed parameters (number of timetables, headways, scheduled 
delay and punctuality). If the speed of the high-speed trains is increased, these effects grow. The high-speed trains in particular suffer significant delays and are sensitive to changes. For trains with lower priority, the increases result chiefly in longer travel times due to longer or new scheduled stops. Timetable flexibility and space for new slots are reduced.

Speed mix is shown to affect the highly-utilised railway line most. By increasing the number of services, stops and high-speed trains' maximum speed, the speed differences increase and capacity decreases, which forces trains with lower priority to make more or longer stops in order to let faster trains pass. This causes the speed variances to increase again, making the timetable less reliable. The traffic mix has a greater impact on capacity than the number of trains per hour.

Strategies to reduce the negative effects have been found. Measures that adjust the speed levels of the different services in particular give positive impacts. Even grouping similar services in the timetable or reducing primary delays, e.g. at stations, are shown to have valuable effects. However, satisfactory delay reduction cannot be achieved with any of the strategies and it has to be kept in mind that some of these strategies clash with the market demand for fast, regular relations. Combining strategies can give better reliability and flexibility, but no complete normalisation of the effects that increasing speed and traffic has. Shorter distance between overtakings is desirable for increasing timetable flexibility and makes it possible to run more trains. However, the effects on punctuality and delays are small.

\section{References}

[1] Gröna Tåget, www.gronataget.se

[2] Lindner, T., Applicability of the analytical UIC Code 406 compression method for evaluating line and station capacity. Journal of Rail Transport Planning Management, 1(1). Pp. 49-57, 2011.

[3] Radtke, A. and Bendfeldt, J-P Handling of railway operation problems with RailSys. Proc. of the 5th World Congress on Rail Research, Cologne, 2001.

[4] Sipilä, H., Simulation of modified timetables for high speed trains Stockholm-Göteborg. Proc. of the $1^{\text {st }}$ International Conference on Road and Rail Infrastructure, Opatija, 2010.

[5] Lindfeldt, A. Investigating the impact of timetable properties on delay propagation on a double-track line using extensive simulation. Proc. of the 11th International Conference and Exhibition Railway Engineering, London, 2011.

[6] Lindfeldt, O., Analysis of capacity on double-track railway lines. Transport Planning and Technology, 34(4), 2011.

[7] Vromans, M.J.C.M., Reliability of Railway Systems. Erasmus Research Institute of Management, Rotterdam, 2005.

[8] Vromans, M.J.C.M., Dekker, R. and Kroon, L.G., Reliability and Heterogeneity of Railway Services. European Journal of Operational Research, 172 (2), pp. 647-665, 2006. 
[9] Castillo, E., Gallego, I., Ureña J.M. and Coronado, J.M., Timetabling optimization of a single railway track line with sensitivity analysis. TOP, 17(2), pp. 256-287, 2009.

[10] Sipilä, H., Calibration of Simulation Model on the Southern main line in Sweden, Proc. of the 11th International Conference and Exhibition Railway Engineering, London, 2011.

[11] Trafikverket. Kapacitetsutnyttjande hösten 2011 (map). www.trafikverket.se

[12] Trafikverket. Kapacitetsbegränsningar hösten 2011 (map). www.trafikverket.se

[13] Andersson, A. and Fröidh, O., Green Train. Concept Proposal for a Scandinavian High-speed Train. Final Report. Part A and B, KTH Railway Group, Stockholm, 2012.

[14] Sipilä, H., Körtidsberäkningar för Gröna tåget: analys av tågkonfigurationer, KTH Railway Group, Stockholm, 2008. 